\title{
The Efficiency of self-employed general practitioners and factors affecting it: a study in Iran
}

\author{
Razie Hajibagheri ${ }^{1}$, Farhad Lotfi ${ }^{2}$ and Mohsen Bayati ${ }^{3^{*}}$ (])
}

\begin{abstract}
Objective: Physicians as an economic firm make use of available resources such as time, human forces and space to provide healthcare services. The current study aimed at estimating the technical efficiency of Iranian self-employed general practitioners (GPs) and its effective factors using data envelopment analysis and regression analysis.

Results: About 2\% of the GPs were fully efficient and the remaining (98\%) were inefficient. Almost, 2.09\% of the physicians had constant returns to scale, and $31.41 \%$ and $66.49 \%$ of them had increasing and decreasing returns to scale, respectively. According to the regression estimates, gender (female) $(\beta=3.776, P=0.072)$, age $(\beta=0.475, P=0.013)$, practice experience $(\beta=-0.477, P=0.015)$, contract with the insurer $(\beta=-6.475, P=0.005)$ and economic expectations ( $\beta=1.939, P=0.014$ ) showed significant effect on GPs inefficiency. Most of the GPs surveyed did not optimally allocate their time and physical and human resources to provide their services. Female GPs, older ones, those with fewer practice experience, those with higher economic expectations, and the GPs with no insurance contract were more inefficient. Increasing the insurance coverage of self-employed GPs and providing them with training in office economic management can reduce their inefficiency.
\end{abstract}

Keywords: Efficiency, General practitioner, Medical economics, Economic competition, Data envelopment analysis

\section{Introduction}

One of the most important components of any health system is physician workforces [1], who make vital decisions in the health care system. In fact, as they play the role of agents to direct other medical inputs, their decisions significantly affect the quantity, quality, and costs of the health care services. Therefore, physicians' behavior is a fundamental issue in health economics, as it will affect other functions and goals of the health system [2].

A general practitioner's (GP) visit is of great importance because it is often the start point for benefitting

*Correspondence: bayatim@sums.ac.ir; bayatim66@gmail.com ${ }^{3}$ Health Human Resources Research Center, School of Management \& Information Sciences, Shiraz University of Medical Sciences, Almas Building, Alley 29, Qasrodasht Ave, Shiraz, Iran

Full list of author information is available at the end of the article from other health services [3, 4]. In low-income countries and for low-income individuals, referral to a GP is one of the cost-effective ways to receive primary care in order to reduce extra costs and unnecessary referrals to specialists and ultimately hospitalization rates [5]. Despite the role of GPs in community health, given the significant impact of physicians on resource orientation as well as the likelihood of induced demands and the large amount of resources to be reimbursed, outputs are not as efficient and of sufficient quality [6].

Considering resource constraints and cost pressures, especially in the social sectors of countries, optimal use of resources and efficiency enhancement are emphasized [7]. Health care is an economic commodity. Patients play the role of consumers, and health care providers are suppliers [8]. Among health care providers, physicians as one of the most important firm provide health services. Like

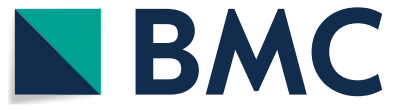

(c) The Author(s) 2020. This article is licensed under a Creative Commons Attribution 4.0 International License, which permits use, sharing, adaptation, distribution and reproduction in any medium or format, as long as you give appropriate credit to the original author(s) and the source, provide a link to the Creative Commons licence, and indicate if changes were made. The images or other third party material in this article are included in the article's Creative Commons licence, unless indicated otherwise in a credit line to the material. If material is not included in the article's Creative Commons licence and your intended use is not permitted by statutory regulation or exceeds the permitted use, you will need to obtain permission directly from the copyright holder. To view a copy of this licence, visit http://creativeco mmons.org/licenses/by/4.0/. The Creative Commons Public Domain Dedication waiver (http://creativecommons.org/publicdomain/ zero/1.0/) applies to the data made available in this article, unless otherwise stated in a credit line to the data. 
any other firm, physicians make use of available resources such as time, human forces and space to provide healthcare products. There are various theories about the economic behavior of physicians as a firm, including profit maximization model, utility maximization model, and target income hypothesis [9]. Efficiency is a factor on which most firms in today's world rely to compete [10]. Hence, to evaluate economic performance of physicians, like other firms, it is helpful to examine the concept of efficiency.

Very little research has been done on this issue. A study by Heimeshoff et al. [11] in 2013 examined the costs and technical efficiency of 3126 physicians in Germany from 2006 to 2008. Also, Olsen et al. [12] in Denmark (2011) estimated the production frontier of GPs considering the number of physician visits and a production criterion as outputs. Estimating the physician production function in the US, Reinhardt showed that physicians could produce more than they were doing and increase their productivity [13]. DeFelice and Bradford investigated the inefficiency of individual and group production of 924 GPs [14].

To the knowledge of the researchers, no studies had been done on the efficiency of physicians in developing countries.

GPs in Iran, as the most important providers of primary health care, play a significant role in the overall functioning of the health system. Given the volume and variety of services provided to the community by the GPs, and as healthcare delivery processes are usually initiated by them, they have a significant role in the overall volume of resources consumed in the health sector. There were about 86,000 GPs in Iran in 2019, accounting for more than $65 \%$ of all physicians in the country $[2,15]$. Studies showed that over half of the GPs were working in the private sector, most of whom were self-employed and office-based [16]. Thus, this study aimed to evaluate the efficiency of GPs in Iran and the factors affecting it.

\section{Main text \\ Methods}

The present cross-sectional study made use of the data provided by Bayati et al. [17] in a survey in which a researcher-made tool and the convenient sampling method were used to collect the data of 666 GPs. The present study was restricted to self-employed physicians in the private sector.

In the present study, we examined self-employed GPs' $(\mathrm{n}=232)$ technical, managerial and scale efficiency using the Data Envelopment Analysis (DEA) method as well as the variable returns to scale assumptions and an output-oriented model (the goal of private GPs is usually product enhancement). General DEA model is a follows:

$$
\begin{aligned}
& \operatorname{Max} h_{0}=\frac{\sum_{r=1}^{s} u_{r} y_{r 0}}{\sum_{i=1}^{m} v_{i} x_{i 0}}, \\
& \text { Subject to }: \frac{\sum_{r=1}^{s} u_{r} y_{r j}}{\sum_{i=1}^{m} v_{i} x_{i j}} \leq 1 ; u_{r}, v_{i} \geq 0 ; \\
& \quad r=1, \ldots, s ; i=1, \ldots, m ; j=1, \ldots, n
\end{aligned}
$$

where $y, x, u$ and $v$ are output, input, output weight and input weight, respectively.

Based on previous studies [11-14] and the available data, physician's working hours, number of staff, and space were considered as input variables, and the number of visits was considered as output in the present study. In this study, technical inefficiencies of the GPs were estimated. So efficiency could be given the score 1 (full efficiency) and more than one (inefficiency).

After estimating the GPs' inefficiency scores, univariate analysis was performed to compare inefficiency scores based on demographic, practice and viewpoint factors.

After that, the factors affecting inefficiency were evaluated using the following regression model:

$$
I E_{i}=\beta_{0}+\beta_{1} D_{i}+\beta_{2} P_{i}+\beta_{3} V_{i}+u_{i} i=1,2, \ldots, 232
$$

In which IE is the GPs' technical inefficiency (dependent variable), D stands for demographic factors including gender, age, and marital status, $P$ represents the variables related to medical practice including competition in the market, medical practice experience, location of practice, contract with insurers, and the existence of a pharmacy near the practice site, and $\mathrm{V}$ shows economic perspectives (i.e. GPs' economic expectations). $u_{i}$ represents the regression error, $i$ shows the GPs, and $\beta s$ is the coefficients of the model.

Competition in the market was measured by the number of centers offering similar services near the location of the physician's practice (other physicians' offices, clinics and hospitals). Economic expectations is a variable derived from three items, including economic expectations of the community, the physician's family, and the physician him/herself [18]. The mentioned model was estimated using ordinary least square (OLS). F statistic was estimated to determine overall significance of model.

The Stata14.2 software was used for data analysis.

\section{Results}

Table 1 shows the descriptive statistics of the demographic variables, the ones related their medical practice and the attitudes of the GPs studied.

About $2 \%$ of the GPs were fully efficient and the remaining (98\%) were inefficient. 
Table 1 Descriptive statistics of studied self-employed GPs characteristics

\begin{tabular}{|c|c|c|}
\hline Variables & Frequency & Percent \\
\hline \multicolumn{3}{|l|}{ Gender } \\
\hline Male & 134 & 57.76 \\
\hline Female & 98 & 42.24 \\
\hline \multicolumn{3}{|l|}{ Marital status } \\
\hline Single & 25 & 10.87 \\
\hline Married & 205 & 89.13 \\
\hline \multicolumn{3}{|l|}{ Age (years) } \\
\hline $26-35$ & 27 & 11.79 \\
\hline $36-45$ & 65 & 28.38 \\
\hline $46-55$ & 93 & 40.61 \\
\hline $56 \leq$ & 44 & 19.21 \\
\hline \multicolumn{3}{|l|}{ Practice experience (years) } \\
\hline $1-5$ & 30 & 13.27 \\
\hline $6-10$ & 35 & 15.49 \\
\hline $11-15$ & 43 & 19.03 \\
\hline $16-20$ & 57 & 25.22 \\
\hline$\leq 21$ & 61 & 26.99 \\
\hline \multicolumn{3}{|l|}{ Practice location } \\
\hline Tehran & 90 & 44.12 \\
\hline Other province centers & 52 & 25.49 \\
\hline Other cities and villages & 62 & 30.39 \\
\hline \multicolumn{3}{|l|}{ Contract with the insurer } \\
\hline No & 80 & 37.74 \\
\hline Yes & 132 & 62.26 \\
\hline \multicolumn{3}{|l|}{ Economic expectations } \\
\hline Very low & 39 & 17.49 \\
\hline Low & 50 & 22.42 \\
\hline Moderate & 4 & 1.79 \\
\hline High & 84 & 37.67 \\
\hline Very high & 46 & 20.63 \\
\hline \multicolumn{3}{|c|}{$\begin{array}{l}\text { Number of centers offering similar services near the location of the GP's } \\
\text { practice }\end{array}$} \\
\hline No & 4 & 1.74 \\
\hline $1-2$ & 49 & 21.30 \\
\hline $3-5$ & 76 & 33.04 \\
\hline $5 \geq$ & 101 & 43.91 \\
\hline \multicolumn{3}{|c|}{ Existence of a pharmacy near the practice site } \\
\hline No & 4 & 1.73 \\
\hline Yes & 227 & 98.27 \\
\hline
\end{tabular}

Based on the results, $2.09 \%$ of the physicians had constant returns to scale, and $31.41 \%$ and $66.49 \%$ of them had increasing and decreasing returns to scale, respectively.

The univariate analysis (Table 2) showed, the physicians' inefficiency scores were significantly different based on gender, medical practice experience, location of practice, economic expectations, and contract with insurance organizations $(\mathrm{P}<0.01)$.
According to the regression results (Table 3), gender had a significant relationship with inefficiency, and women were more inefficient than men. Age had also a positive relationship with inefficiency, and increased age would increase inefficiency. The experience of medical practice had a negative relationship with inefficiency, and its increase was followed by decreased inefficiency. The doctors who had contracts with insurance organizations were less inefficient. Furthermore, economic expectations had a positive relationship with inefficiency, and physicians who had higher economic expectations were more inefficient.

\section{Discussion}

The maximum scores of scale, managerial and technical inefficiency of the GPs evaluated in this study were 32.5 , 88.103 and 88.425 , respectively. There were wide inefficiency score changes. In addition, the scores indicated that the physicians were in a better situation in terms of scale efficiency than managerial efficiency. Scale efficiency indicated how close the physicians were to the optimal scale of production (constant returns to scale). Given the status of returns to scale, most of the physicians needed to change (increase or decrease) their visitation rate to provide services at an optimum production scale. About $2 \%$ of the GPs were fully efficient technically and the remaining $98 \%$ were inefficient. This showed that they did not use their resources properly (time, physical and human resources).

A study carried out by Olsen et al. [12] in 2011 on GPs in Denmark showed that the mean technical efficiency was 0.79 to 0.84 . Similar to the current study, the range of efficiency scores was wide and many GPs were inefficient. However, their findings somewhat differ from those of the present study, the reason for which could be different outputs, inputs, sample sizes, and socioeconomic conditions. In the Olsen study the stochastic frontier analysis was used, the inputs were the physicians' and nurses' working hours and the outputs were the number of visits and the total productivity index. The sample size was 1749 as well.

According to the findings of the present study, gender, age, medical practice experience, contract with insurance companies, and economic expectations had a significant relationship with GPs' inefficiency.

Women were more inefficient than men (at 10 percent significance level). Only a similar study reported a related finding; the study by Olsen et al. [12] on Danish GPs showed that women were more inefficient than men when considering the number of visits as an output. It seems that due to women's different preferences, expectations and financial responsibility compared to men [19, 20], they pay less attention to the economic management 
Table 2 GPs' inefficiency scores based on demographic, practice and viewpoint factors

\begin{tabular}{|c|c|c|c|c|c|c|}
\hline Variables & $\begin{array}{l}\text { Technical efficiency } \\
\text { mean (CD) }\end{array}$ & P-value & $\begin{array}{l}\text { Managerial } \\
\text { efficiency } \\
\text { mean (CD) }\end{array}$ & P-value & $\begin{array}{l}\text { Scale efficiency } \\
\text { mean (CD) }\end{array}$ & P-value \\
\hline Overall & $8.735(11.253)$ & & $7.559(10.565)$ & & $1.413(2.450)$ & \\
\hline \multicolumn{7}{|l|}{ Gender } \\
\hline Male & 6.791 (8.159) & 0.002 & $6.117(7.716)$ & 0.014 & $1.153(.298)$ & 0.058 \\
\hline Female & $11.94(14.54)$ & & $9.942(13.803)$ & & $1.844(3.952)$ & \\
\hline \multicolumn{7}{|l|}{ Marital status } \\
\hline Single & 11.598 (19.548) & 0.249 & $10.618(19.583)$ & 0.188 & $1.328(.741)$ & 0.8712 \\
\hline Married & $8.447(9.995)$ & & $7.242(9.105)$ & & $1.425(2.579)$ & \\
\hline \multicolumn{7}{|l|}{ Age (years) } \\
\hline $26-35$ & $13.241(13.572)$ & 0.271 & $11.742(13.731)$ & 0.274 & $1.683(2.538)$ & 0.561 \\
\hline $36-45$ & $8.420(7.574)$ & & $6.669(5.378)$ & & $1.755(4.316)$ & \\
\hline $46-55$ & 8.188 (12.946) & & $7.236(12.310)$ & & $1.207(0.417)$ & \\
\hline $56 \leq$ & $7.864(9.966)$ & & $7.221(9.837)$ & & $1.215(0.561)$ & \\
\hline \multicolumn{7}{|l|}{ Practice experience (years) } \\
\hline $1-5$ & $11.208(11.204)$ & 0.000 & $9.880(11.079)$ & 0.001 & $1.632(2.432)$ & 0.144 \\
\hline $6-10$ & 17.387 (20.799) & & $14.031(20.244)$ & & $2.434(5.727)$ & \\
\hline $11-15$ & $7.788(8.709)$ & & $7.249(8.624)$ & & $1.086(0.101)$ & \\
\hline $16-20$ & $6.572(6.437)$ & & $5.619(5.171)$ & & $1.211(0.416)$ & \\
\hline$\leq 21$ & $5.404(4.248)$ & & $4.889(4.105)$ & & $1.142(0.231)$ & \\
\hline \multicolumn{7}{|l|}{ Practice location } \\
\hline Tehran & $12.027(15.966)$ & 0.010 & $10.216(15.206)$ & 0.034 & $1.823(4.006)$ & 0.270 \\
\hline Other province center & $7.806(7.991)$ & & $6.697(7.178)$ & & $1.228(0.500)$ & \\
\hline Other cities and villages & $5.809(5.599)$ & & $5.228(5.355)$ & & $1.127(0.200)$ & \\
\hline \multicolumn{7}{|l|}{ Contract with the insurer } \\
\hline No & $15.344(17.011)$ & 0.000 & $12.984(16.398)$ & 0.000 & $1.917(4.182)$ & 0.060 \\
\hline Yes & $5.432(3.726)$ & & $4.836(3.505)$ & & $1.166(.355)$ & \\
\hline \multicolumn{7}{|l|}{ Economic expectations } \\
\hline Very low & $5.648(2.928)$ & 0.002 & $4.854(2.789)$ & 0.0009 & $1.287(0.707)$ & 0.726 \\
\hline Low & $8.378(10.553)$ & & $6.981(9.664)$ & & $1.747(3.915)$ & \\
\hline Moderate & $28.647(22.167)$ & & $27.536(23.186)$ & & $1.186(0.331)$ & \\
\hline High & $8.000(8.819)$ & & $6.853(7.280)$ & & $1.182(0.326)$ & \\
\hline Very high & $10.662(16.083)$ & & $9.685(16.033)$ & & $1.183(0.303)$ & \\
\hline \multicolumn{7}{|c|}{ Number of centers offering similar services near the location of the GP's practice } \\
\hline No & $5.715(2.926)$ & 0.098 & $4.334(2.250)$ & 0.063 & $1.362(0.193)$ & 0.453 \\
\hline $1-2$ & $8.635(10.178)$ & & $7.116(8.740)$ & & $1.933(4.858)$ & \\
\hline $3-5$ & $6.325(5.260)$ & & $5.253(4.080)$ & & $1.378(1.524)$ & \\
\hline$\leq 5$ & $10.938(14.761)$ & & $9.854(14.311)$ & & $1.176(0.366)$ & \\
\hline \multicolumn{7}{|c|}{ Existence of a pharmacy near the practice site } \\
\hline No & $6.142(2.972)$ & 0.688 & $5.136(1.664)$ & 0.690 & $1.159(.182)$ & 0.857 \\
\hline Yes & 8.777 (11.334) & & 7.598 (10.644) & & 1.417 (2.470) & \\
\hline
\end{tabular}

and efficiency of their practices. A study showed that male GPs in Iran worked approximately $50 \mathrm{~h}$ more than women per month and had about 80 more visits [17]. Male physicians had also higher earnings expectations than female ones [9]. In other studies carried out in other countries, such as France and Australia, female GPs were also less productive than males [21,22].
The results showed that GP' inefficiency increased with age. A similar study by Olsen et al. [12] showed that age had a significant relationship with inefficiency of GPs. Another study showed that GPs in Iran worked longer hours as their ages increased, but had fewer visits [17]. Doctors themselves choose how long to work and whether to have leisure time or to visit patients. In other 
Table 3 Regression estimates for factors affecting technical inefficiency of Iranian self-employed GPs

\begin{tabular}{lll}
\hline Explanatory variable & Coefficient & P-value \\
\hline Constant & -6.925 & 0.521 \\
Gender & Reference & \\
Male & 3.776 & 0.072 \\
Female & 0.475 & 0.013 \\
Age (years) & -.477 & 0.015 \\
Practice experience (years) & & \\
Practice location & Reference \\
Tehran & -2.351 & \\
Other province centers & -2.433 & 0.299 \\
Other cities and villages & & 0.324 \\
Contract with the insurer & Reference \\
No & -6.475 & \\
Yes & 1.939 & 0.005 \\
Economic expectations & 1.710 & 0.014 \\
Competition in the market & 0.127 \\
Existence of a pharmacy near the practice site & \\
No & Reference & \\
Yes & -1.734 & 0.794 \\
Overall significance & & \\
F statistic & 5.42 & 0.000 \\
R $^{2}$ & 0.262 & \\
\hline
\end{tabular}

words, economic behavior of physicians varies according to their utility function. Besides, based on the target income hypothesis, differences in their financial expectations can lead to differences in their performance [23]. Older physicians may have reached their desired financial levels and reduce their activities. On the other hand, studies outside the health sector have noted that as people age, their willingness and also ability to work (especially in hard jobs) decrease $[24,25]$.

The results showed that an increase in medical practice experience would lead to decreased inefficiency of GPs. Trust are the most important element of the physician-patient relationship [26]. Patients are more trusted in experienced physicians and refer to them; thus, more experienced physicians have higher visit production efficiency. Besides, as more experienced physicians have higher financial expectations $[9,27]$, they are likely to produce more with available resources.

One important point is that physicians' inefficiency was negatively correlated with the practice experience and positively with age. In the present study, since the variables of age and practice experience were both included in the regression model, their effects could be interpreted purely. This indicates that more experienced physicians are not necessarily older.
Having a contract with insurance company had a negative relationship with inefficiency. In other words, doctors who had a contract with an insurer were less inefficient. Since the patients having an insurance look for doctors who have insurance contract to be able to use the insurance coverage advantages, there is a higher demand for physicians who are contracted with insurance organizations. The positive impact of insurance coverage on the demand for health services have been confirmed in various studies $[28,29]$. Therefore, in equal conditions, physicians who have insurance contracts have more visits and are more efficient.

The results also showed that general practitioners with higher economic expectations were more inefficient. This suggests that when other conditions (gender, age, work experience, insurance contract, competition, and location of practice) were controlled, higher economic expectations would not necessarily mean more optimal visit production, and on the contrary, such physicians were less efficient.

\section{Limitations}

The present study had some limitations. First, since there was no accurate sampling frame and address list for the GPs in the private sector, the convenience sampling method was used, which might reduce the generalizability of the results. The second limitation was the relativity of the efficiency concept. Efficiency estimates depends on the number and type of inputs and outputs, sample size, model assumptions (input- driven or output-driven), and model estimation method. If these items change, efficiency score will change, too. Therefore, the findings should be interpreted with caution. The third limitation was the lack of a complete output criterion for the physicians' performance. The output criterion in this study, like in many other studies, was visits. Visits could not show the quality of services and the difference between the services provided by physicians. The last limitation is that because of data unavailability, we could not assess the effect of patient's preferences on GP's efficiency. Patient's characteristics such as their preferences, severity of disease, sociodemographic features and economic status can affect demand for GPs visits and so their efficiency. In this regards, only one research considered patient characteristic as a compound variable from some demographic and socio-economic factors [12].

\section{Abbreviations}

DEA: Data envelopment analysis; GP: General practitioner; OLS: Ordinary least square. 


\section{Acknowledgements}

The authors are grateful to the Prof. Arash Rashidian (director of information, evidence and research in the Eastern Mediterranean Region of the World Health Organization) for his valuable support.

\section{Authors' contributions}

Study design: $\mathrm{MB}, \mathrm{FL}$; Data analysis: $\mathrm{MB}, \mathrm{RH}$; Data interpretation: $\mathrm{MB}, \mathrm{FL}, \mathrm{RH}$; Manuscript drafting: $M B, R H$; Final review of manuscript: $M B, F L, R H$. All authors read and approved the final manuscript.

\section{Funding}

This study is financially supported by Shiraz University of Medical Sciences with Grant Number 18193.

\section{Availability of data and materials}

The data used in this study are not publicly available because the participants were promised that the raw data would remain confidential. However they are available from the corresponding author on reasonable request.

\section{Ethics approval and consent to participate}

This study was conducted in accordance with the International Declaration of Helsinki. The study protocol was approved by the Ethics Committee of Shiraz University of Medical Sciences (IR.SUMS.REC.1398.218). All participants were informed of their right to withdraw from the study at any time. All participants also gave their written consent to participate in the study.

\section{Consent to publish}

Not applicable.

\section{Competing interests}

The authors declare that they have no competing interest.

\section{Author details}

${ }^{1}$ Student Research Committee, Shiraz University of Medical Sciences, Shiraz, Iran. ${ }^{2}$ Health Human Resources Research Center, School of Management \& Information Sciences, Shiraz University of Medical Sciences, Shiraz, Iran. ${ }^{3}$ Health Human Resources Research Center, School of Management \& Information Sciences, Shiraz University of Medical Sciences, Almas Building, Alley 29, Qasrodasht Ave, Shiraz, Iran.

\section{Received: 11 April 2020 Accepted: 20 May 2020}

Published online: 01 June 2020

\section{References}

1. Lugo Palacios D. Analysis of the effectiveness of primary care services and of hospital efficiency in the Mexican health care system: London School of Hygiene \& Tropical Medicine; 2016.

2. Meysamie A, Montazeri A. General physician job satisfaction in public and private sectors. Iran Occup Health. 2014;11(5):74-85.

3. Lischko AM. Cost sharing: do employees understand cost sharing and do increases in cost sharing really have an impact on the utilization of health care services?: ProQuest; 2008

4. Pezij J-w. Access to the general practitioner: a study examining the access to the general practitioner from the patient's point of view, a comparison of three forms of organizations: University of Twente; 2009.

5. Van Doorslaer E, Koolman X, Puffer F. Equity in the use of physician visits in OECD countries: has equal treatment for equal need been achieved. Measuring up: improving health system performance in OECD countries. 2002.

6. Stathakis E, Brachos K, Abatzianis C, Bandekas D, Mouroutsos S. A smart approach to measuring the performance-efficiency, effectiveness and productivity-of the general University Hospital of Alexandroupolis-GUHA using Special Indicators. J Eng Sci Technol Rev. 2017;10(2):141-9.

7. Gupta S, Verhoeven M. The efficiency of government expenditure: experiences from Africa. J Policy Model. 2001;23(4):433-67.
8. McGuire TG. Physician agency. Handbook of health economics. 1: Elsevier; 2000. p. 461-536.

9. Bayati M, Rashidian A. Target income and its determinants for general physicians: an instrumental variables approach. Int J Healthcare Manage. 2018;11(3):260-8.

10. Schneider JE, Ohsfeldt RL. The role of markets and competition in health care reform initiatives to improve efficiency and enhance access to care. Cumb L Rev. 2006;37:479.

11. Heimeshoff M, Schreyögg J, Kwietniewski L. Cost and technical efficiency of physician practices: a stochastic frontier approach using panel data. Health Care Manage Sci. 2014;17(2):150-61.

12. Olsen KR, Gyrd-Hansen D, Sørensen TH, Kristensen T, Vedsted P, Street A. Organisational determinants of production and efficiency in general practice: a population-based study. Eur J Health Econ. 2013;14(2):267-76.

13. Reinhardt U. A production function for physician services. The review of Economics and Statistics. 1972, p 55-66.

14. DeFelice LC, Bradford WD. Relative inefficiencies in production between solo and group practice physicians. Health Econ. 1997;6(5):455-65.

15. Tunstall-Pedoe H. Preventing chronic diseases. A vital investment: WHO Global Report. Geneva: World Health Organization, 2005. p 200. CHF 30.00. ISBN 924 1563001. Oxford University Press; 2006. Also published on http://www.who.int/chp/chronic_disease_report/en.

16. Bayati M, Rashidian A, Zandian H, Alipoori S. Dual practice and multiple job holding among Iranian general practitioners: rate and effective factors. Int J Health Plan Manag. 2020;35(3):799-807.

17. Bayati M, Rashidian A. Descriptive study of economic behavior of general practitioners in Iran: practice income, hours of work, and patient visits. Int J Prevent Med. 2019;10:217.

18. Bayati M, Rashidian A, Sari AA, Emamgholipour S. General practitioners' views on key factors affecting their desired income: a principal component analysis approach. Med J Islamic Repub Iran. 2017:31:41.

19. Rizzo JA, Zeckhauser RJ. Pushing incomes to reference points: why do male doctors earn more? J Econ Behav Organ. 2007;63(3):514-36.

20. Spencer ES, Deal AM, Pruthi NR, Gonzalez CM, Kirby EW, Langston J, et al. Gender differences in compensation, job satisfaction and other practice patterns in urology. J Urol. 2016;195(2):450-5.

21. Cheng TC, Scott A, Jeon SH, Kalb G, Humphreys J, Joyce C. What factors influence the earnings of general practitioners and medical specialists? Evidence from the medicine in Australia: balancing employment and life survey. Health Econ. 2012;21(11):1300-17.

22. Dumontet $M$, Le Vaillant M, Franc C. What determines the income gap between French male and female GPs-the role of medical practices. BMC Fam Pract. 2012;13(1):94.

23. Samson AL. Low income self employed GPS apflU, Department of Economics, University of York.: HEDG. University of York; 2010.

24. Van den Berg TI, Elders LA, Burdorf A. The effects of work-related and individual factors on work ability: a systematic review. Promotion of work ability towards productive aging. Boca Raton: CRC Press; 2008. p. 25-8.

25. Alcantara MA, Sampaio RF, Assuncao AA, Silva FCM. Work Ability: using structural equation modeling to assess the effects of aging, health and work on the population of Brazilian municipal employees. Work. 2014;49(3):465-72.

26. Gray BH. Trust and trustworthy care in the managed care era. Health Aff. 1997;16(1):34-49.

27. Rizzo JA, Blumenthal D. Physician income targets: new evidence on an old controversy. Inquiry. 1994;31 (4 (Winter 1994/95)):394-404.

28. Mathew S, Mash R. Exploring the beliefs and attitudes of private general practitioners towards national health insurance in Cape Town, South Africa. Afr J Primary Health Care Fam Med. 2019;11(1):1-10.

29. Ha NV, Nguyen VTA, My Anh BT, Nguyen TD. Health insurance cards and health care services utilization: evidence from children in mountainous regions of Vietnam. Global Pediatr Health. 2019:6:2333794X19843917.

\section{Publisher's Note}

Springer Nature remains neutral with regard to jurisdictional claims in published maps and institutional affiliations. 